\title{
ANÁLISIS DE LA DINÁMICA COSTERA VINCULADA A LA URBANIZACIÓN: LOS CASOS DE PLAYA UNIÓN Y PLAYA MAGAGNA (PROVINCIA DE CHUBUT, PATAGONIA, ARGENTINA)
}

\author{
María Paula Ferrari \\ Estudiante de Doctorado en Geografía \\ Universidad Nacional de la Patagonia San Juan Bosco (Trelew, Provincia de Chubut, \\ Argentina) \\ Correo electrónico: mapaulaferrari@ yahoo.com.ar
}

Recibido: 9 de diciembre de 2011. Aceptado: 12 de enero de 2012

\begin{abstract}
RESUMEN
Dentro de las principales actividades antrópicas que impactan o transforman el ambiente natural se encuentra el proceso de urbanización, y el ambiente costero no está exento de estas intervenciones. En la dinámica costera no solo intervienen procesos naturales sino también actuaciones humanas, ambos generadores de condiciones de peligro. Si bien existen en Playa Unión y Playa Magagna (Provincia de Chubut, Patagonia Argentina) condiciones de peligrosidad natural vinculadas a procesos geomorfológicos, en los últimos años se ha registrado una creciente ocupación del espacio para urbanización que ha generado diversas transformaciones territoriales en el ambiente costero, acentuando los procesos de peligrosidad natural ya existentes en el área de estudio. El objetivo del trabajo es caracterizar los procesos de la dinámica costera que generan condiciones de peligro en las costas de Playa Unión y Playa Magagna. Para dicha caracterización se articuló el trabajo de campo y la indagación bibliográfica.
\end{abstract}

Palabras clave: Costas, Urbanización, Transformaciones territoriales, Peligros.

\section{COASTAL DYNAMICS ANALYSIS RELATED TO URBANIZATION: THE CASES OF PLAYA UNION AND PLAYA MAGAGNA (CHUBUT PROVINCE, PATAGONIA, ARGENTINA)}

\begin{abstract}
The process of urbanization is one of the main human activities that impact or transform the natural environment, and the coastal environment is not exempt from these interventions. Coastal dynamic processes involve not only natural but also human actions, both yielders of hazardous conditions. Even though in Playa Unión and Playa Magagna (Chubut Province, Patagonia Argentina) exist natural hazard conditions related to geomorphological processes, recent years have experimented an increasing use of space for urbanization which developed several territorial changes in the coastal environment accentuating the natural hazard processes existing in the study area. The objective of this studio is to characterize the dynamic coastal processes that generate
\end{abstract}


hazardous conditions in the shores of Playa Unión and Playa Magagna. This characterization was based on field-work, literature and document research.

Keywords: Coasts, Urbanization, Territorial Changes, Hazards.

\title{
ANÁLISE DA DINÂMICA COSTEIRA LIDAGA À URBANIZAÇÃO: CASOS DE PLAYA UNIÓN E PLAYA MAGAGNA (PROVÍNCIA DE CHUBUT, PATAGONIA, ARGENTINA)
}

\begin{abstract}
RESUMO
Dentre as principais atividades humanas que impactam ou transformar o ambiente natural é o processo de urbanização, e do ambiente costeiro não está isento de tais intervenções. Na dinâmica costeira envolvido processos naturais e ações humanas, dois geradores de situações de perigo. Apesar de existirem em Playa Unión e Playa Magagna (Província de Chubut, Patagonia Argentina) condições naturais de perigo ligados à processos gemorfológicos, nos últimos anos tem havido uma crescente ocupação do espaço para urbanização que gerou várias transformações territoriais no ambiente costeiro, acentuando processos naturais de perigo existentes na área de estudo. $\mathrm{O}$ objetivo deste trabalho é caracterizar os processos da dinâmica costeira que geram condições perigosas na costa de Playa Unión e Playa Magagna. Para esta caracterização tem combinado trabalho de campo e investigação bibliográfica.

Palavras-chave: Costas, Urbanização, Transformações territoriais, Perigos.
\end{abstract}

\section{INTRODUCCIÓN}

Estudios de la dinámica costera destacan que el sector costero de Patagonia se encuentra sometido a fenómenos de erosión generalizada, presentando en el extremo sur los valores máximos de erosión costera (Codignotto, 2004) mientras que hacia el norte el fenómeno erosivo se atenúa, con algunas excepciones como ser en el sector comprendido entre Isla Escondida y Playas Magagna y Unión en la provincia de Chubut. La actual morfología costera en Patagonia es relíctica, ya que se originó a partir de condiciones climáticas que se dieron en el pasado reciente, hecho que explica que actualmente la costa patagónica manifieste una tendencia evolutiva hacia la erosión de las geoformas presentes (Kokot, 2004).

Pese a la baja densidad poblacional, la urbanización y los usos recreativos y turísticos del espacio costero patagónico se han extendido de manera constante, modificando el paisaje original. A diferencia de la costa de la provincia de Buenos Aires, donde el proceso de urbanización durante la mayor parte del siglo XX estuvo fuertemente motivado por el turismo masivo de sol y playa (Dadon, 2002), en la costa patagónica la urbanización del frente litoral se vincula principalmente a las actividades portuarias, comerciales y extractivas, a partir de las cuales se han desarrollado asentamientos costeros para uso urbano residencial y de turismo. Ello ha favorecido la consecuente aparición de problemas ambientales entre el medio natural y el medio social, representado por el desarrollo urbano, que atenta contra un uso sustentable del recurso costero. 
Por lo tanto, la franja costera patagónica aparece como un espacio geográfico donde los dos componentes que lo definen, medio físico y medio social-construido, presentan una red de interacciones asociados a tipos de conflictividad. En ciertos sectores estas interacciones derivan en situaciones de riesgo (en el sentido de Cardona, 1993), las que necesitan de un análisis adecuado a fin de evitar o minimizar los impactos negativos sobre el ambiente y el deterioro de los recursos naturales como consecuencia del desarrollo costero.

En el caso de Playa Unión y Playa Magagna, localizadas en el sector noreste de la provincia de Chubut, próximas a la desembocadura del río homónimo, la interacción entre procesos naturales y actuaciones sociales plantea una problemática compleja vinculada con los riesgos de origen natural e inducidos antrópicamente. La dinámica de los procesos de erosión que dominan la evolución geomorfológica del área y el patrón de ocupación territorial identificado, sustentan la caracterización de dicho litoral como un área de riesgo. En este trabajo se analizan los procesos de la dinámica costera que generan condiciones de peligrosidad tanto natural como inducida antrópicamente en ambas playas.

Playa Magagna corresponde a una angosta franja de costa conformada por tres pequeños asentamientos costeros (Bonita, El Faro y Los Cangrejales) donde predominan actividades de ocio, turismo y urbano-residenciales. El área ha evidenciado en los últimos años un destacado incremento de la urbanización, y una creciente demanda de espacio para asentar diversos usos de suelo. A ello se suma que el desarrollo de esta franja litoral no está afectado a normatividad que ordene o limite su utilización.

Por su parte, Playa Unión corresponde a un asentamiento costero de mayor importancia, y en continuidad con Playa Magagna, desarrollado a lo largo de un extenso litoral de mar abierto, afectado por notorios eventos erosivos, manifestados en el retroceso de la línea de costa. El proceso de erosión no es un fenómeno nuevo, ya que ha sido un proceso recurrente en el sector desde hace aproximadamente 3800 años (Monti, 2000). En tiempos más recientes, la intervención antrópica ha contribuido a agravar el proceso erosivo en Playa Unión. La urbanización de este frente litoral desde principios del siglo XX favoreció la desaparición de las dunas, indispensables para el equilibrio natural de la costa. Asimismo, la construcción del Dique Florentino Ameghino en el año 1963 aguas arriba de la desembocadura del río Chubut- disminuyó notablemente el aporte de material sedimentario del río a la costa. La construcción del Puerto de Rawson en el período 1960-1963 y su modificación en el año 2001, alteró el normal equilibrio de aporte y arrastre de sedimentos que se produce en la línea de costa producto de la deriva litoral. Por lo tanto, la intervención humana no sólo ha modificado la dinámica de los procesos costeros, y con ello su peligrosidad potencial, sino también ha impactado en las condiciones de vulnerabilidad del medio social y construido expuesto a los peligros. 


\section{Figura1. Localización de Playa Unión y Playa Magagna (Chubut, Patagonia Argentina)}
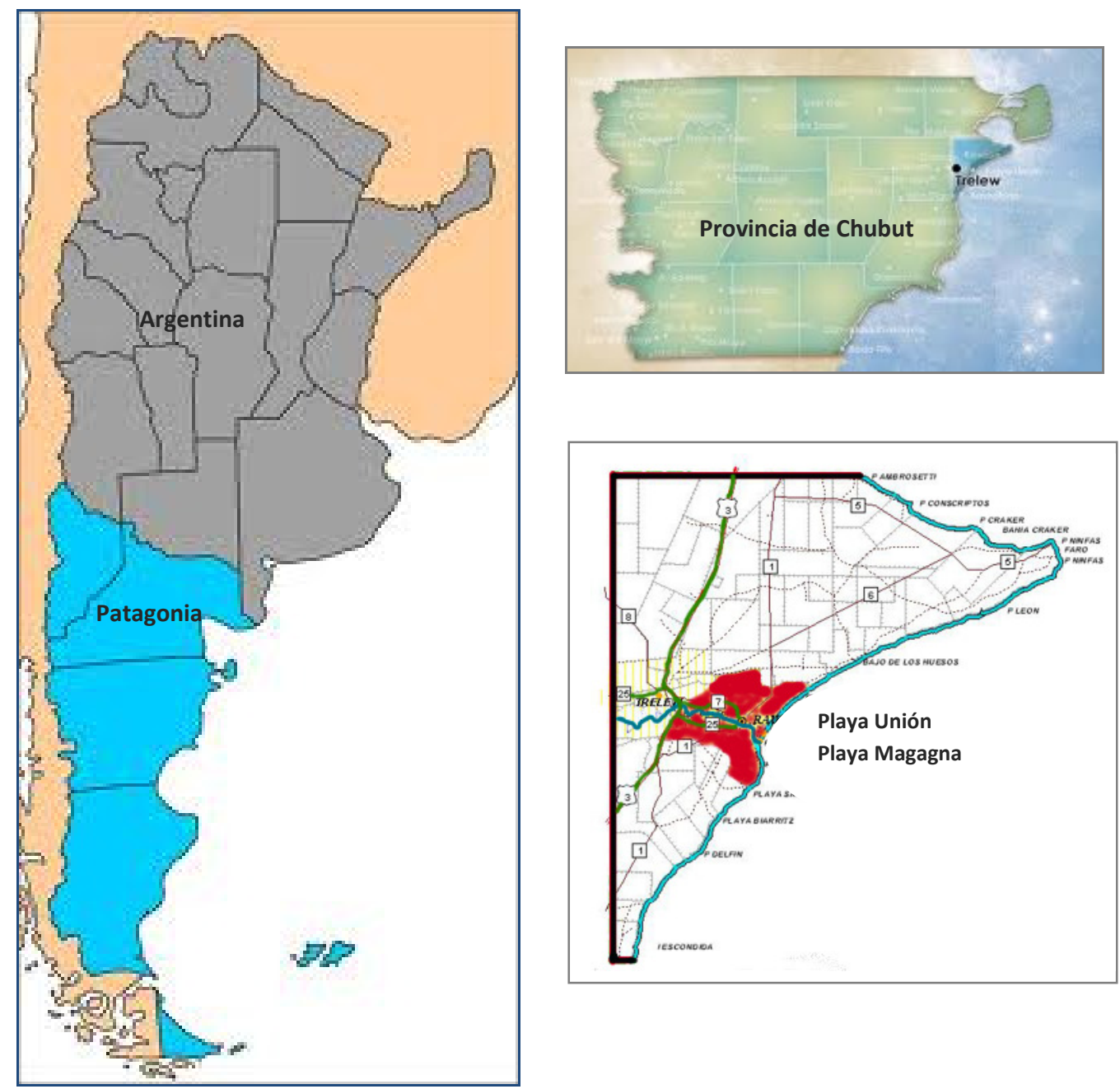

Fuente: Elaboración propia.

\section{APROXIMACIÓN TEÓRICO-CONCEPTUAL}

En la dinámica costera no solo intervienen procesos naturales sino también procesos o actuaciones humanas, ambos generadores de condiciones de peligro. Según Cardona (1993), la peligrosidad o amenaza es a la probabilidad de ocurrencia de un fenómeno natural o tecnológico, que puede presentarse en un sitio específico y en un tiempo determinado, produciendo efectos adversos en personas, bienes o medio ambiente. Si bien no todos los fenómenos son considerados peligrosos, si lo son aquellos que presentan la posibilidad de ocasionar daños o perjuicios a la sociedad. Como señalan Romero y Maskrey (1997), la peligrosidad de un fenómeno se refiere a la potencialidad de daño del mismo.

Ahora bien, el riesgo se define como "el grado de pérdidas y/o daños esperados debido a la ocurrencia de un fenómeno peligroso desde la perspectiva humana y a la presencia de condiciones de vulnerabilidad en los elementos o contextos expuestos a dicho fenómeno" 
(Cardona, 1993, p. 27). Por lo tanto, el riesgo alude a un daño en potencia o un daño probable, y se configuran situaciones de riesgo cuando se produce la convergencia, en tiempo y espacio, de sus dos componentes principales, peligro (o amenaza) y vulnerabilidad. Wilches Chaux (1993) y Calvo García-Tornel (1997) señalan que la vulnerabilidad es un concepto eminentemente social, relacionado con la dificultad de absorción de los cambios como consecuencia de características propias de los elementos (o contextos) expuestos a un determinado peligro.

Si bien la erosión como proceso natural constituye un estado normal en el desarrollo del paisaje (Codignotto, 2004), existen sitios donde la erosión puede presentarse como un proceso dominante como consecuencia de la acción realizada por los diversos agentes erosivos en el modelado del terreno (erosión natural). Cuando en un escenario con estas características se introduce la presencia del hombre, dichos fenómenos erosivos dominantes se convierten en procesos de peligro, en tanto pueden generar daños a las personas. Así mismo, la intervención del hombre puede acentuar o acelerar los procesos erosivos naturales (erosión antrópica); y la principal intervención antrópica que impacta y transforma el ambiente natural es el proceso de urbanización, del cual el ambiente costero no está exento de experimentar.

Según Lavell (1996), las amenazas o peligros de origen natural se definen como aquellas manifestaciones de procesos de la naturaleza vinculadas a la dinámica geológica, geomorfológica, climática u oceánica en los cuales no existe intervención humana directa o significativa posible. Este mismo autor sostiene que algunos procesos naturales tienen una expresión o incidencia que es socialmente inducida -y que denomina amenazas socio-naturales-, es decir, que se producen o bien se acentúan por algún tipo de intervención humana sobre la naturaleza, y que en la mayoría de los casos suelen confundirse con eventos propiamente naturales. Ejemplos de expresiones más comunes de procesos de peligro inducidos antrópicamente son los deslizamientos, hundimientos, inundaciones, incendios rurales y agotamiento de acuíferos.

\section{PLAYA MAGAGNA}

\section{Diagnóstico de las condiciones de peligrosidad natural}

Respecto a los procesos de peligrosidad natural presentes en Playa Magagna, se han realizado estudios basados en una zonificación costera geomorfológica, a partir de una aproximación de escalas que reconoce ambientes, sistemas y unidades morfodinámicas. El ambiente morfodinámico se delimitó sobre la base de características climáticas y morfoestructura regional. Para identificar los sistemas morfodinámicos se tuvieron en cuenta atributos de homogeneidad litológica y proceso geomorfológico dominante de los macro relieves expuestos; mientras que cada unidad morfodinámica se definió a partir del material geológico superficial, geoforma y condición de peligrosidad geomorfológica. Cada unidad morfodinámica identificada en Playa Magagna presenta diversos procesos de peligrosidad geomorfológica vinculados con el retroceso de la costa por erosión marina, y con los derrumbes de la barranca occidental por erosión hídrica-pluvial y remoción en masa. 
En línea con la caracterización de los procesos naturales de peligro para Playa Magagna, Monti (1999) ha confeccionado perfiles de peligrosidad para cada uno de los procesos naturales identificados, a partir de una valoración cualitativa de seis componentes de peligrosidad propuesta por Burton et al (1978): frecuencia, duración, extensión areal, velocidad de aparición, dispersión espacial y espaciado temporal. Dichos perfiles de peligrosidad ubican a la remoción en masa como un fenómeno intensivo, con impactos ambientales inmediatos, mientras que la erosión hídrica presentaría en la zona una condición menos intensiva, comportándose incluso en ciertas ocasiones como un proceso penetrante. En cambio, la erosión marina aparece como un típico proceso penetrante, cuyos impactos se evidencian por efecto acumulativo, salvo en el caso de tormentas costeras extremas, donde los impactos sobre la costa se hacen mucho más inmediatos.

La dinámica de los procesos geomorfológicos activos que modelan la línea de costa en Playa Magagna caracterizan un sustrato en erosión activa, tanto por efecto del mar sobre la base de los acantilados activos y los frentes de las planicies de acreción sedimentaria cuaternaria, como por la acción de la escorrentía superficial (producto de excedentes pluviales), y por fenómenos de remoción en masa sobre las barrancas que limitan el sector al oeste. Por lo tanto, como se observa los procesos de peligrosidad natural presentes en Playa Magagna, están representados por la erosión costera en su conjunto: constituida por la acción combinada de la erosión hídrica-pluvial, los procesos de remoción en masa y la erosión marina vinculada al retroceso de la línea de costa. Todos ellos se constituyen en procesos de la dinámica costera que según la perspectiva humana pueden ser considerados peligrosos.

\section{Diagnóstico de las condiciones de peligrosidad inducida antrópicamente}

Si bien existen en Playa Magagna condiciones de peligrosidad natural vinculadas a procesos geomorfológicos, en los últimos años se ha registrado una creciente ocupación del espacio para urbanización. Esta situación generó diversas intervenciones humanas en el ambiente costero que han contribuido a acentuar los procesos de peligro natural ya existentes en el área, y como consecuencia, manifiestan la presencia de amenazas socionaturales en el sentido de Lavell (1996).

Las intervenciones humanas que se presentan como indicadores de peligrosidad inducida antrópicamente en Playa Magagna corresponden a las siguientes:

\section{La rectificación o verticalización de las laderas de los acantilados (barrancas)}

Este es un tipo de modificación antrópica que contribuye a inducir procesos de remoción en masa en las laderas de las barrancas, y paralelamente, a profundizar las cárcavas en el tope de las mismas. La rectificación o verticalización de las laderas de las barrancas presenta diversas modalidades, ejemplificadas en la figura 2 . La verticalización del tipo a, se ha evidenciado en los tres asentamientos de Playa Magagna, en el que personas con propiedad en el sector (con residencia permanente o transitoria) han modificado la disposición natural de los materiales que conforman las laderas de las barrancas con el propósito, en la mayoría de los casos, de ampliar el fondo de sus terrenos. El caso más emblemático se presenta en una parcela de Playa Los 
Cangrejales, donde la rectificación de la ladera de la barranca (acantilado) alcanza los 10 metros de altura aproximadamente (ver fotografía 1).

Figura 2. Modalidades de verticalización de laderas.
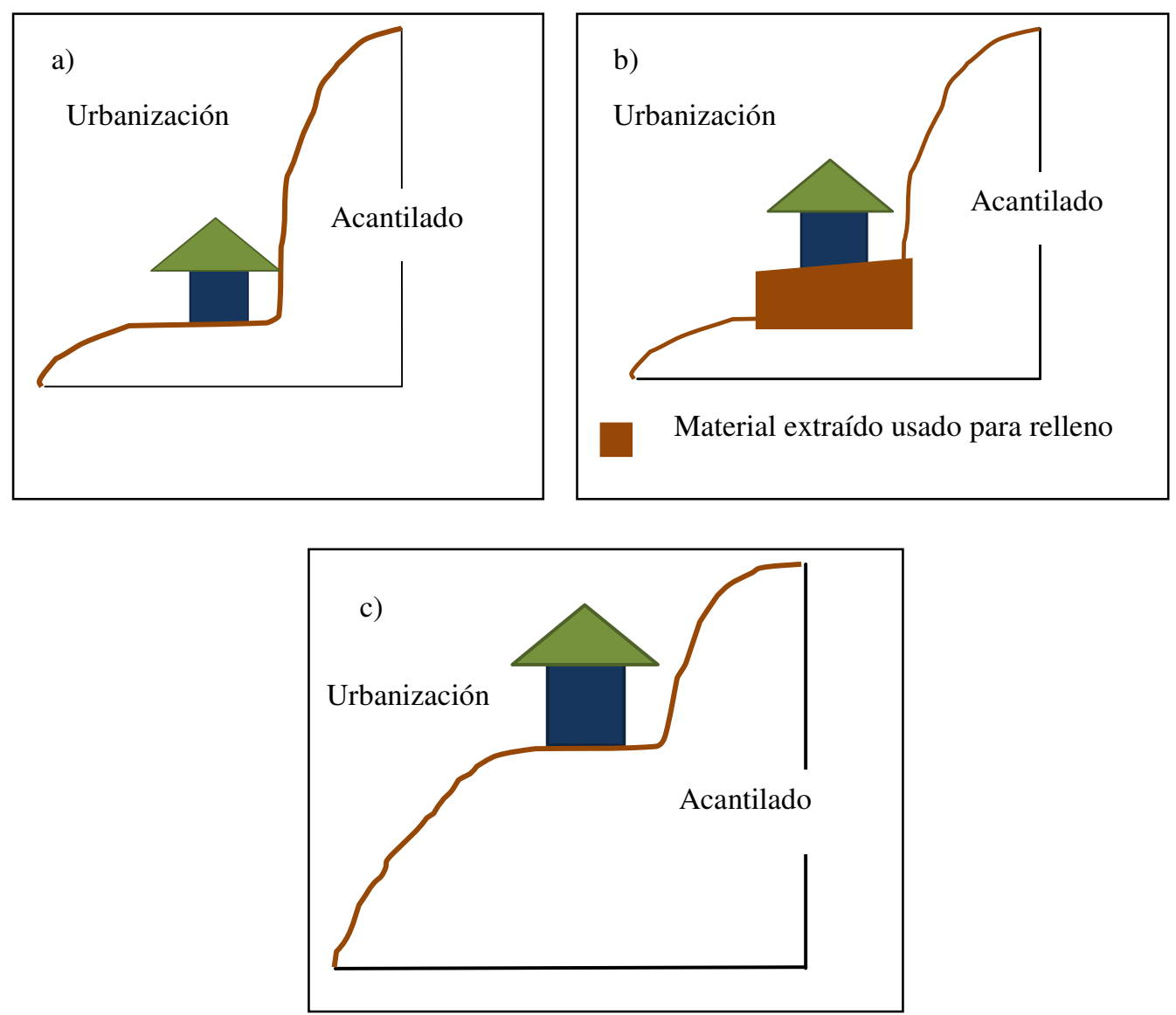

Fuente: Elaboración propia.

Fotografía 1. Verticalización de ladera en Playa Los Cangrejales.

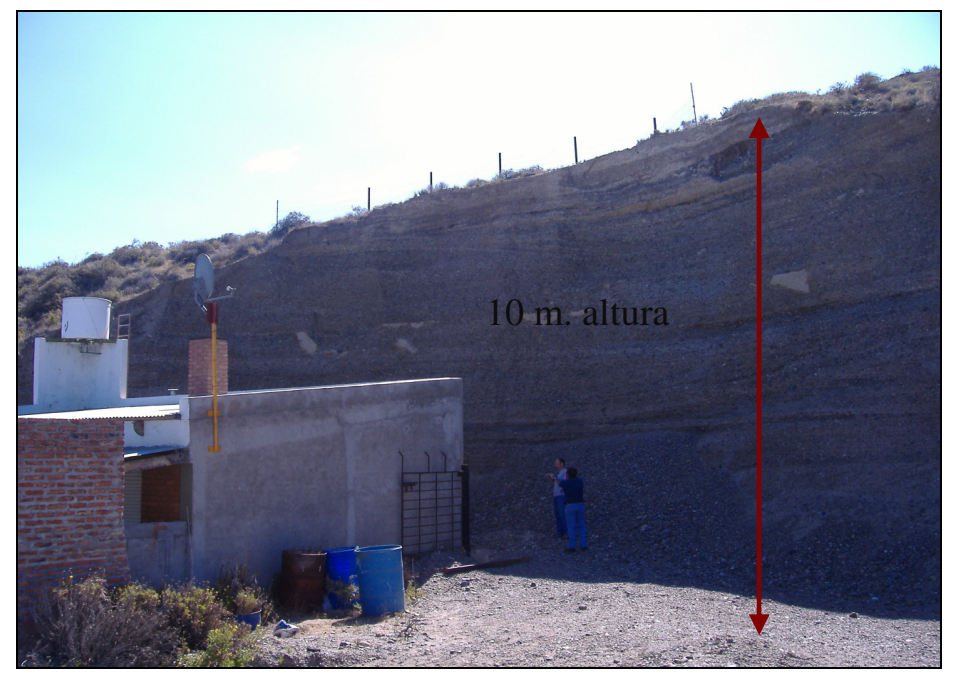

Autora: María Paula Ferrari (Diciembre de 2007). 
La verticalización de laderas es un tipo de intervención antrópica que no sólo es realizada frecuentemente, sino que además, no considera los procesos de carcavamiento, la erosión hídrica y la presencia de cañadones, potenciando los impactos desfavorables propios de la verticalización sobre las viviendas. Como se observa en la fotografía 2, la rectificación de la ladera se efectuó en cercanías a un cañadón en Playa Cangrejales.

\section{Fotografía 2. Verticalización de ladera próxima a cañadón Playa Cangrejales.}

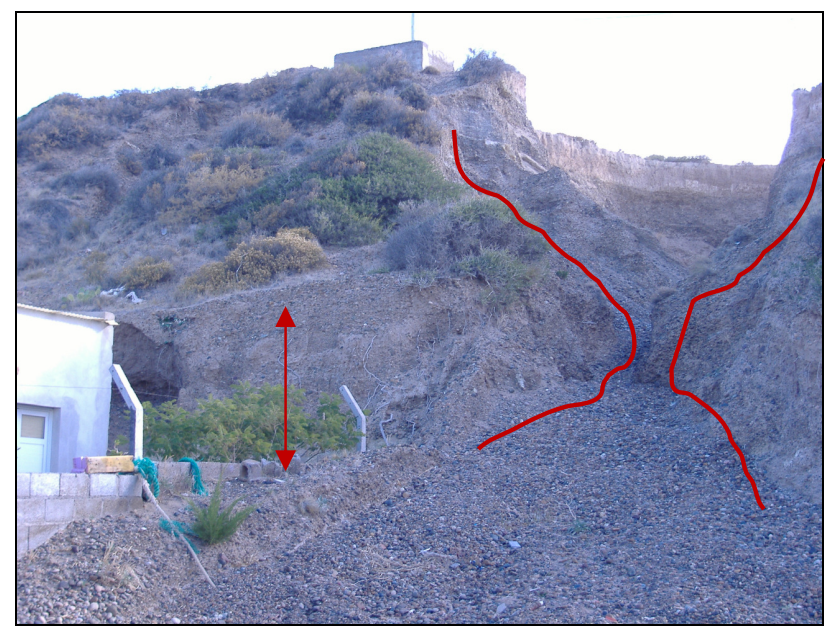

Autora: María Paula Ferrari (Mayo de 2011)

Otra modalidad de verticalización se vinculada a la extracción y compactación de materiales de las laderas de los acantilados (ver figura 2 b). En la mayoría de los casos los propietarios extraen y compactan material de las laderas con el objetivo de ampliar terreno sobre el fondo de las parcelas (invasión de laderas en situación de ilegalidad) y paralelamente, utilizar el material de relleno para emplazar a mayor altura las viviendas $\mathrm{y}$, de esa manera, obtener una mejor vista panorámica al mar. La fotografía 3 muestra un ejemplo de extracción y compactación de materiales utilizados como relleno en una parcela de Playa El Faro. Puede visualizarse el emplazamiento de las viviendas entre los 5 y 7 metros por encima del nivel del camino costero.

Fotografía 3. Extracción y compactación de materiales de laderas

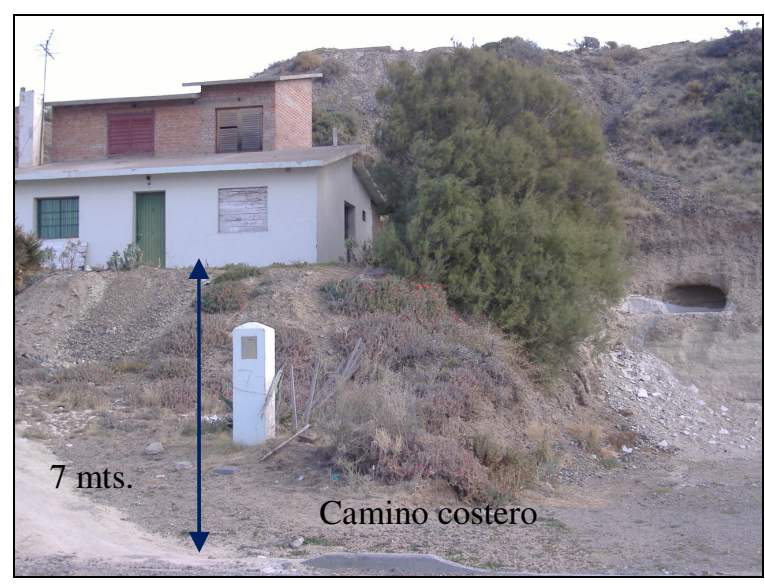

Autora: María Paula Ferrari (Mayo de 2011). 


\section{El tránsito vehicular sobre cañadones para acceder a las playas}

Esta intervención antrópica sobre los cañadones tiene su origen desde que se conformaron los asentamientos costeros de Playa Magagna, donde a principios de siglo XX los primeros visitantes accedían a la costa con carruajes a través de los cañadones. Ante la existencia de acantilados de fuerte pendiente y altura variable que no supera los 25 metros a lo largo de la costa, los cañadones se constituyen en los lugares de mejor acceso a las playas debido al aprovechamiento de la excavación natural del terreno. El establecimiento de caminos sobre los cañadones ha favorecido la escorrentía superficial por compactación y, paralelamente, ha promovido los deslizamientos de las laderas de las barrancas en sectores próximos a los cañadones de acceso vehicular.

\section{El tránsito peatonal sobre los acantilados (barrancas)}

Este tipo de intervención antrópica es realizada tanto por residente como turistas. Si bien está prohibido el transito con vehículos todo terreno (cuatriciclos) en la zona costera de Playa Magagna, incluidas las barrancas (Ordenanza Municipal $N^{\circ}$ 5.163), se carece de normativa respecto al tránsito peatonal sobre las laderas de las mismas. En algunos sectores de la playa se ha observado la existencia de escalinatas construidas por los propietarios con materiales diversos (ver fotografía 4) que promueven al tránsito peatonal sobre las laderas de las barrancas; intervención que no solo favorece la escorrentía superficial por compactación y los deslizamientos de las laderas, sino que además, contribuye a la formación de cárcavas en el tope de los acantilados.

Fotografía 4. Escalinata sobre ladera P. Bonita (material: gomas).

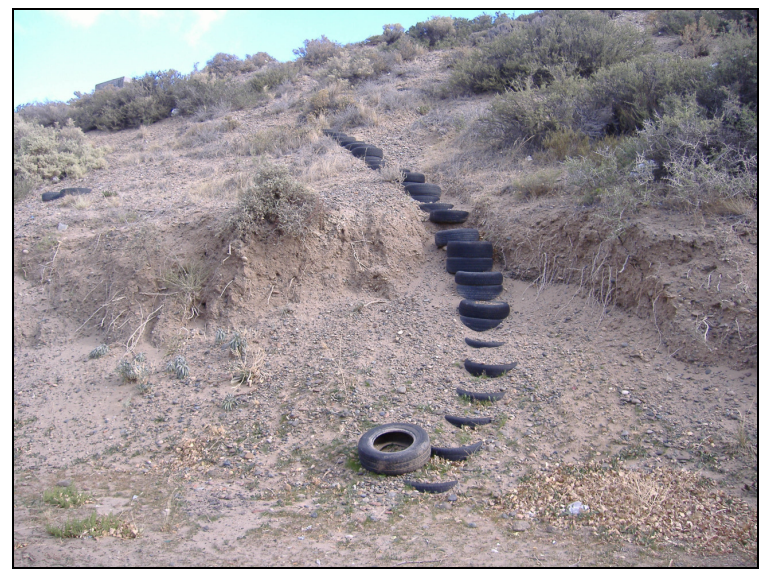

Autora: María Paula Ferrari (Mayo de 2011)

\section{La modificación del sustrato original de la terraza marina de acumulación}

La modificación antrópica de la terraza marina de acumulación en Playa Bonita se vincula a la sustracción de la vegetación original allí presente (especies de la estepa patagónica) para el emplazamiento del predio donde todos los años se realiza la Fiesta del Pulpo. Mediante recitales al aire libre, feria de artesanías, venta de comida y 
productos diversos, y la elección de la reina del pulpo, el evento fue adquiriendo popularidad desde su primer edición en el año 2008 hasta la actualidad, pero a la vez generando ciertos impactos no deseados. En el aspecto físico-natural se evidencia la modificación del sustrato original de Playa Bonita, para el emplazamiento del escenario y los puestos de venta, lo cual resulta preocupante, atendiendo los problemas de fragilidad costera que caracterizan el sector. Así mismo, la modificación de la terraza marina de acumulación no solo se debe a la sustracción de la vegetación original para el emplazamiento del escenario y puestos de venta, sino también al hecho de que el sector es utilizado para acampar por quienes asisten al evento, con la particularidad de que dicha actividad no está reglamentada, es decir, se realiza en forma libre y sin control alguno por parte de la Municipalidad de Rawson o del Complejo de Administración de Playa Magagna.

Por lo tanto, la intervención en esta unidad morfodinámica ha contribuido a disminuir la infiltración y favorecer la escorrentía superficial ${ }^{1}$, situación que promueve diversos procesos de peligro: la erosión eólica, la erosión hídrica y, al mismo tiempo, la erosión marina, por el hecho de localizarse el sector próximo a la línea de costa.

\section{La construcción de viviendas en la terraza marina de acumulación}

Este tipo de modificación antrópica se refiere a aquellas viviendas que, si bien se instalan sobre la terraza marina de acumulación, se encuentran sobre el tope de los acantilados activos del frente costero. La consecuente compactación del sustrato en el tope de los acantilados labrados sobre los depósitos de rodados de la terraza marina de acumulación, induce procesos de erosión hídrica y remoción en masa, y al mismo tiempo, potencia la erosión marina en dicho sector (ver figura 3 y fotografia 5).

Figura 3

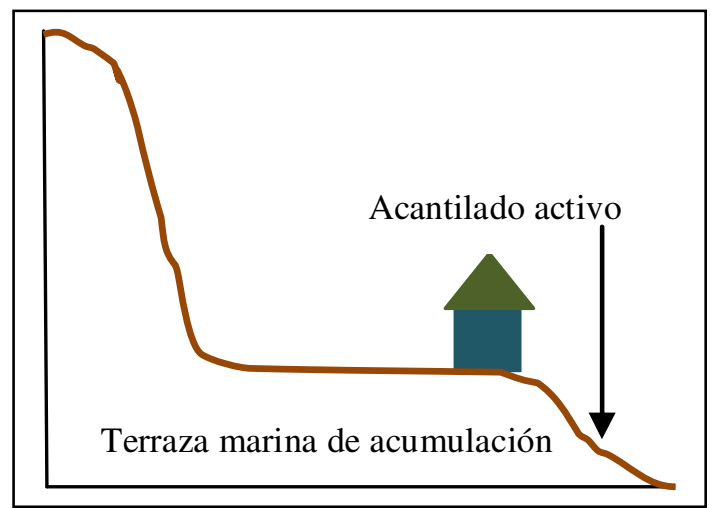

Fuente: Elaboracion propia.

\section{Fotografía 5. Vivienda de frente costero}

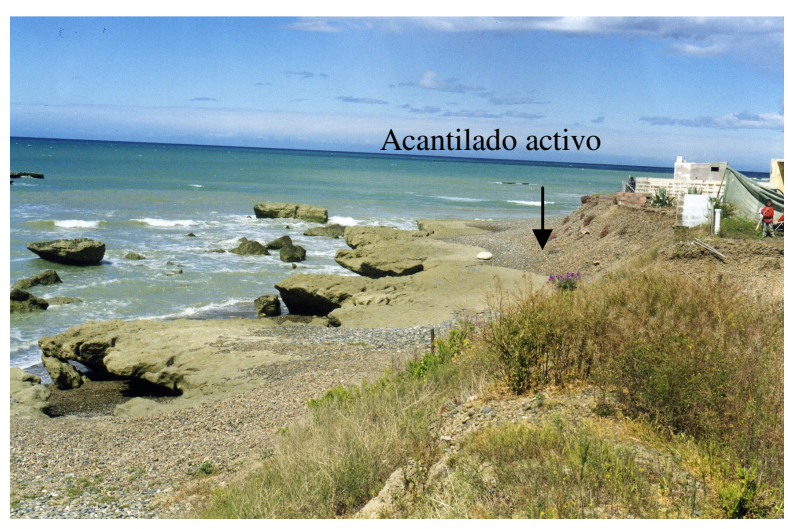

Autora: Alejandro Monti (abril de 1998).

El cuadro 1 sintetiza las características de peligrosidad natural y las intervenciones humanas que inducen procesos de peligro en cada una de las unidades y sistemas

\footnotetext{
${ }^{1}$ El agua de escorrentía ejerce un importante trabajo erosivo con la fuerza de arrastre sobre la superficie del suelo, fuerza que aumenta con ausencia de vegetación (Lagunas, 1995)
} 
morfodinámicos presentes en Playa Magagna.

\section{Cuadro 1. Intervenciones antrópicas que inducen procesos de peligro.}

\begin{tabular}{|c|c|c|c|c|}
\hline Ambiente & Sistemas & $\begin{array}{l}\text { Unidades } \\
\text { morfodinámicas }\end{array}$ & $\begin{array}{l}\text { Peligrosidad geomorfológica } \\
\text { (natural) }\end{array}$ & $\begin{array}{l}\text { Intervenciones humanas } \\
\text { promotoras de Peligrosidad } \\
\text { geomorfológica (inducida) }\end{array}$ \\
\hline \multirow{9}{*}{ 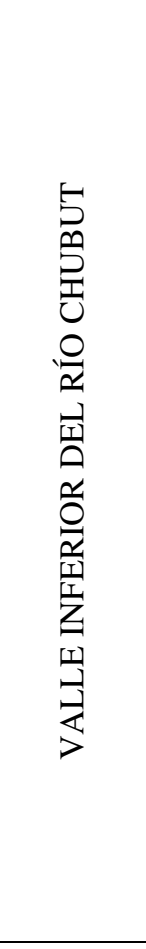 } & \multirow{2}{*}{$\begin{array}{l}\text { Sistema } \\
\text { Aluvio- } \\
\text { Coluvial }\end{array}$} & $\begin{array}{c}\text { Acantilado inactivo } \\
\text { (Barranca) }\end{array}$ & $\begin{array}{c}\text { Erosión hídrica, Remoción en } \\
\text { masa }\end{array}$ & \multirow{2}{*}{$\begin{array}{l}\text { Verticalización de laderas, } \\
\text { Extracción y compactación } \\
\text { materiales de laderas, } \\
\text { Tránsito peatonal y } \\
\text { vehicular sobre cañadones }\end{array}$} \\
\hline & & $\begin{array}{l}\text { Faja de acreción } \\
\text { aluvio-coluvial }\end{array}$ & Remoción en masa & \\
\hline & \multirow{2}{*}{$\begin{array}{l}\text { Sistema } \\
\text { de meseta }\end{array}$} & Médanos costeros & $\begin{array}{l}\text { Inestabilidad del sustrato por } \\
\text { erosión activa }\end{array}$ & \multirow{2}{*}{ No se reconoce } \\
\hline & & $\begin{array}{l}\text { Nivel de rodados y } \\
\text { terrazas Río Chubut }\end{array}$ & Erosión hídrica & \\
\hline & \multirow{5}{*}{$\begin{array}{l}\text { Sistema } \\
\text { Marino- } \\
\text { Litoral }\end{array}$} & $\begin{array}{l}\text { Terraza marina de } \\
\text { acumulación } \\
\text { cordoniforme }\end{array}$ & $\begin{array}{l}\text { Erosión marina con retroceso } \\
\text { de línea de costa. }\end{array}$ & $\begin{array}{c}\text { Modificación sustrato } \\
\text { original y construcción de } \\
\text { viviendas en terraza marina } \\
\text { de acumulación }\end{array}$ \\
\hline & & Plataforma de abrasión & $\begin{array}{c}\text { Erosión marina con retroceso } \\
\text { de línea de costa }\end{array}$ & \multirow{2}{*}{ No se reconoce } \\
\hline & & Acantilados activos 1 & $\begin{array}{c}\text { Erosión hídrica, Remoción en } \\
\text { masa, Erosión marina }\end{array}$ & \\
\hline & & Acantilados activos 2 & $\begin{array}{c}\text { Erosión hídrica, Erosión } \\
\text { marina con retroceso de línea } \\
\text { de costa }\end{array}$ & $\begin{array}{c}\text { Construcción de viviendas } \\
\text { en tope de acantilados del } \\
\text { frente costero }\end{array}$ \\
\hline & & Playa actual & $\begin{array}{c}\text { Erosión marina con retroceso } \\
\text { de línea de costa }\end{array}$ & No se reconoce \\
\hline
\end{tabular}

Fuente: Monti y Ferrari (2011).

\section{PLAYA UNIÓN}

En Playa Unión se distinguen dos formas de erosión vinculadas a la acción del mar como agente erosivo principal: la erosión marina natural y la erosión marina inducida antrópicamente. Se alude a la erosión marina como proceso de peligro en tanto existen elementos del medio social y construido que se exponen a dicho proceso, y por lo tanto, son susceptibles de experimentar modificaciones (daños) producto de su accionar.

\section{Diagnóstico de las condiciones de peligrosidad natural}

El extenso litoral de mar abierto sobre el que se emplaza Playa Unión se encuentra afectado por notorios eventos erosivos, manifestados en el retroceso de la línea de costa. Los primeros indicios de erosión marina en Playa Unión datan desde hace miles de años. Estudios con dataciones radiocarbónicas muestran que la erosión ha estado presente desde hace más 3.800 años antes del presente (Monti 2000, p. 406). Por lo tanto, el proceso de erosión marina no es un fenómeno reciente, ya que ha sido un proceso recurrente en el sector que ha moldeado las geoformas presentes tanto en Bahía Engaño como en cercanías al actual emplazamiento de la ciudad de Rawson. 
Al plantear que el mar genera erosión, se hace referencia a la "modificación (retroceso) de la línea de costa preexistente con la consiguiente pérdida de sedimentos" (Zujar 2001, p. 104). Si el equilibrio natural de aporte y arrastre de sedimentos en la línea de costa se quiebra (con saldo favorable para este último), el nivel de la playa comienza a descender. Al producirse el descenso del suelo las mareas avanzan tierra adentro, situación que promueve un mayor arrastre de la arena que no puede ser compensado por el aporte de materiales a la playa.

La pérdida de sedimentos en Playa Unión se origina por diversas razones, las vinculadas a la dinámica natural corresponden a las siguientes:

a) La acción del viento, que al trasladar los materiales de la playa tierra adentro, contribuye a incrementar la erosión.

b) Las corrientes de mareas que arrastran la arena de la playa, depositándolas en aguas profundas.

c) Las marejadas, es decir, la combinación de eventos de plea mar extraordinarios con el accionar el viento. Como puede observarse en la fotografía 6, correspondiente a un evento de marejada ocurrida en el mes de julio del año 2010 en Playa Unión, la pérdida de material de la playa como consecuencia del accionar del mar ha dejado al descubierto la base del muro costanero.

d) La deriva litoral, corresponde a una corriente costera, que en el área de estudio, adquiere un sentido predominante sur- norte y está directamente relacionada con el oleaje y el viento, siendo a la vez factor de erosión, transporte y alimentación de la playa

Fotografía 6. Efectos de marejada del año 2010 en Playa Unión.

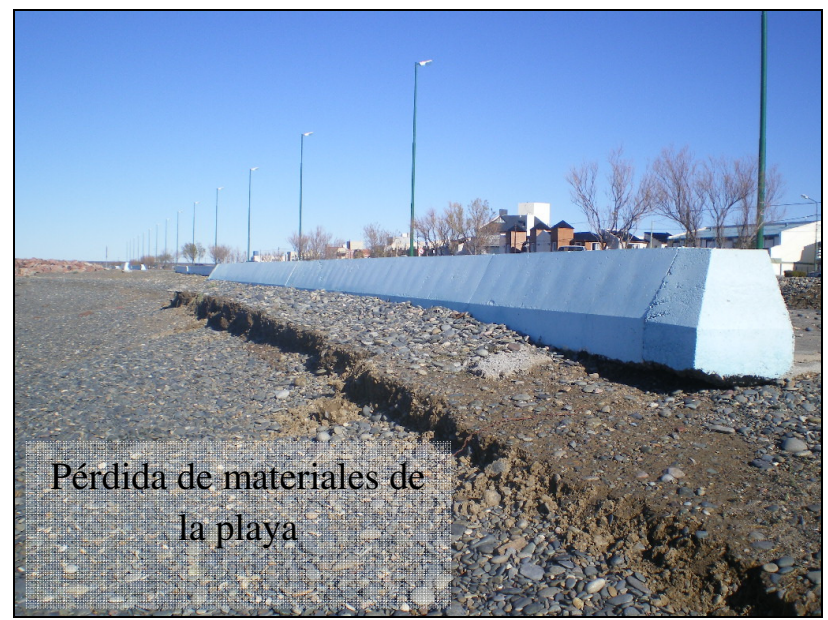

Autora: María Paula Ferrari (Julio de 2010).

\section{Diagnóstico de las condiciones de peligrosidad inducida antrópicamente}

Si bien la erosión marina depende en mayor medida de causas naturales, las intervenciones humanas contribuyen al proceso erosivo. La pérdida de sedimentos de la 
playa por acción del hombre se debe principalmente a la ejecución de obras tales como represas, espigones, puertos, barreras artificiales, y la urbanización sobre las dunas de la playa que alteran la dinámica natural de la costa. Las intervenciones antrópicas que han contribuido a agravar el proceso erosivo en Playa Unión corresponden a las siguientes:

\section{La urbanización sobre el sector de dunas de la playa}

Esta intervención no sólo se inició con las primeras edificaciones a principios del siglo $\mathrm{XX}$, sino también se continúa realizando en la actualidad, principalmente para el establecimiento de balnearios y equipamiento (baños públicos, restaurants, estacionamientos). Al desaparecer las dunas, indispensables para el equilibrio natural de la costa, se altera el efecto amortiguador y de alimentación natural de la playa. Cuando se interrumpe el ciclo playa-médano, la playa queda en un estado de debilitamiento. Al eliminar los médanos, o parte de los mismos, se interfiere el libre desplazamiento del médano, por lo tanto en momentos de marejadas el mar erosiona las infraestructuras donde anteriormente existían médanos. Esta situación se presenta en el frente costero de Playa Unión. La construcción de infraestructura y equipamiento vinculada a la actividad turística se he hecho en un sector donde anteriormente existían médanos.

\section{La construcción del Dique Florentino Ameghino}

En el año 1963 se construye en Dique Florentino Ameghino -aguas arriba de la desembocadura del río Chubut-, a partir de ese momento disminuyó notablemente el aporte de material sedimentario desde el río Chubut a la costa, y por lo tanto, el proceso de alimentación de la playa se alteró.

\section{La construcción del Puerto de Rawson}

El Puerto de Rawson, localizado al sur de Playa Unión, y sus sucesivas modificaciones alteraron el normal equilibrio de aporte y arrastre de sedimentos que se produce en la línea de costa producto de la deriva litoral. La presencia del puerto de Rawson, sumado a las obras de remodelación realizadas, contribuye a acentuar la erosión marina, y por tal motivo, se constituyen en acciones que inducen procesos de peligro (erosión marina inducida antrópicamente).

El Puerto de Rawson se constituye como tal hacia 1930. En el transcurso de los años experimentó diversas transformaciones vinculadas a obras de remodelación del mismo. En el año 1945 -sobre la margen izquierda del río Chubut- se instala el muelle provincial de madera; en el período 1960-1963 se construye las escollera norte y sur; y en el año 1987 se inaugura el muelle de operaciones de la flota pesquera local (flota amarilla). Hacia el año 2001 comienzan una serie de obras de remodelación para la construcción de un Muelle Provincial de Operaciones, que quedó inaugurado en el año 2007. Dichas obras comprendieron la prolongación de la escollera sur y construcción de una escollera norte (construidas con la finalidad de proteger la desembocadura del río generando aguas más tranquilas para la entrada y salida de la flota pesquera), el dragado del lecho del río y la construcción del nuevo muelle de amarre. Así mismo, en el año 2005, como consecuencia de las alteraciones producidas en la deriva litoral, se realiza la 
construcción de un espigón corto al norte del nuevo Puerto Provincial de Operaciones, con la finalidad de detener el proceso erosivo (ver figura 4).

Las obras de remodelación del Puerto de Rawson han obstruido la deriva litoral. Como consecuencia de la presencia de los espigones sur y norte se ha producido la acumulación de sedimentos en el sector el sur, y la erosión en el sector norte de dichas obras. Esto ha obligado a recuperar la playa a través de la colocación de un espigón corto a unos pocos metros al norte de la obra de remodelación del puerto, que no solucionó el problema sino que lo trasladó hacia el norte.

En la figura 4 se observa como la corriente de deriva litoral tiene una dirección surnorte, y por lo tanto, tiende a transportar los sedimentos de la playa en la misma dirección. También puede observarse como los espigones detienen la deriva de playa, atrapando los sedimentos en el sector sur y generando erosión en el sector norte de los mismos. Como respuesta, la deriva debe seguir alimentándose con las arenas del sector norte de las escolleras, ya que no le llegan los aportes del sur, esto es lo que produce la erosión en el sector norte de las escolleras, y por lo tanto agrava el proceso erosivo en Playa Unión.

Isla (2006) plantea que existen diversos métodos para defender la costa. Algunos comprenden obras blandas, que no alteran la dinámica costera ya que proponen la simple reconstitución de la playa original, manteniendo la energía de olas, la composición granulométrica y la pendiente de la playa. Otros métodos comprenden obras duras que modifican la dinámica costera, como ser los muros, espigones, rompeolas, causando reflexión, difracción o refracción de olas incidentes.

Como puede observarse en el cuadro 2, desde comienzos de la década de 1960 en Playa Unión se han adoptado diversos tipos de obras "duras" que han interferido la dinámica costera natural y por consiguiente agravado la erosión de la playa.

Cuadro 2. Síntesis de modificaciones antrópicas del sector costero de Playa Unión.

\begin{tabular}{|c|l|}
\hline Año & \multicolumn{1}{c|}{ Tipo de intervención } \\
\hline $1950-1963$ & Construcción del Dique Florentino Ameghino \\
\hline $1962-1964$ & Construcción del espigón norte de hormigón (antigua escollera norte) \\
\hline $1972-1974$ & Construcción de la escollera sur (antigua escollera sur) \\
\hline 1977 & $\begin{array}{l}\text { Construcción de pantallas experimentales (barreras) en la playa para } \\
\text { atenuar los efectos erosivos }\end{array}$ \\
\hline 1979 & $\begin{array}{l}\text { Construcción de espigón longitudinal al norte de Playa Unión (sector del } \\
\text { ex camping Siglo XXI) }\end{array}$ \\
\hline 2002 & $\begin{array}{l}\text { Finaliza la prolongación de la escollera sur, extendida 265 metros (nueva } \\
\text { escollera sur) y se da inicio al dragado del lecho del río Chubut en su } \\
\text { desembocadura. }\end{array}$ \\
\hline 2003 & Finaliza la ejecución de la nueva escollera norte de 544 metros \\
\hline $2005-2006$ & Construcción del espigón corto perpendicular a la playa. \\
\hline
\end{tabular}

Fuente: Elaboración propia. 
Figura 4. Obras costeras de Playa Unión.

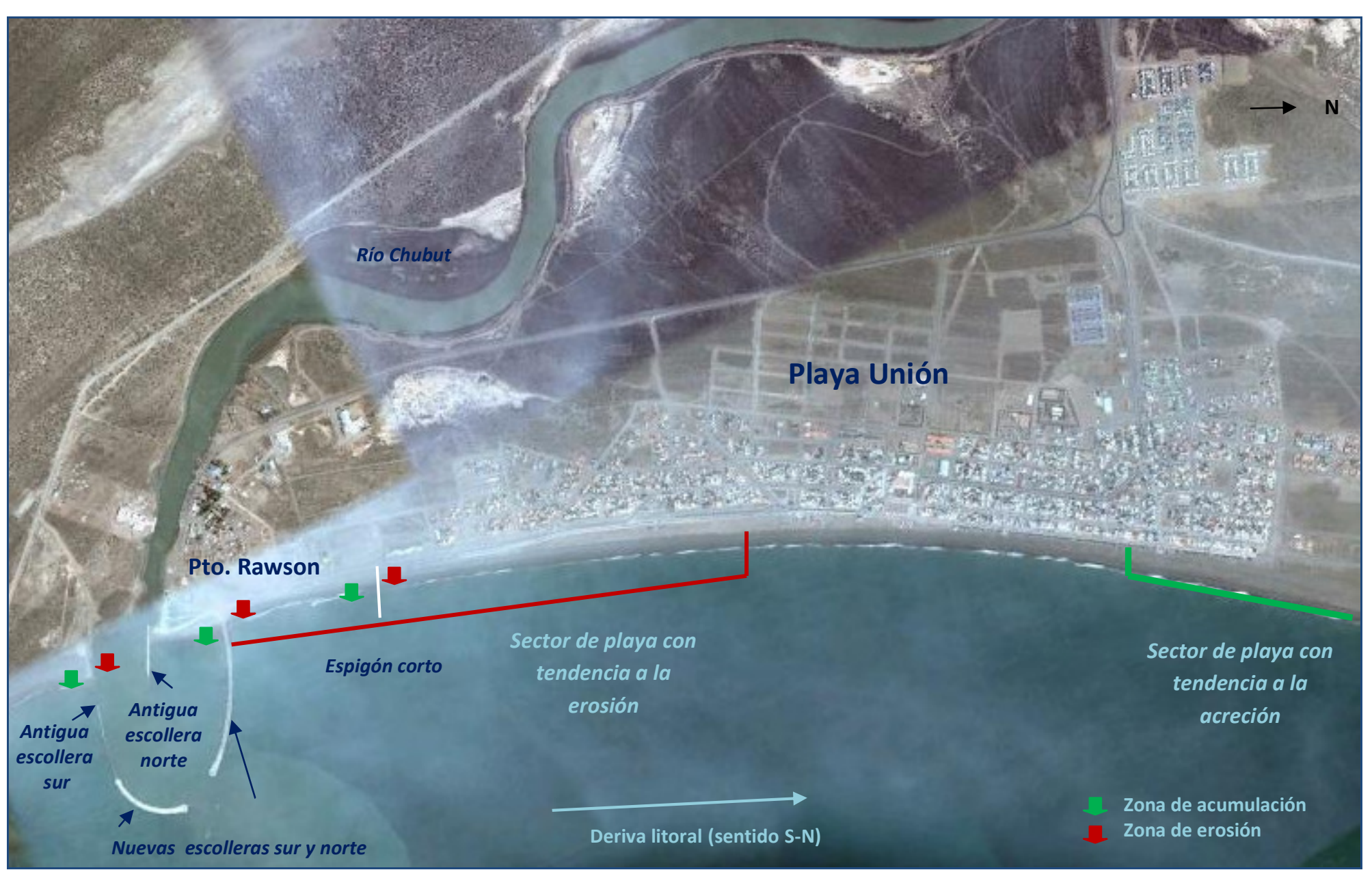

Fuente: Elaboración propia en base a imagen satelital del Google Earth, 2010. 


\section{REFLEXIONES FINALES}

Si bien, para analizar la erosión como fenómeno interviniente en la dinámica del espacio costero es necesario considerar no sólo aspectos vinculados a procesos de la naturaleza, como ser, la topografía, la geomorfología, la energía de olas o la orientación de la costa a las tormentas más frecuentes; en dicho análisis también deben considerarse las intervenciones que el hombre realiza sobre el ambiente costero, y las alteraciones que las mismas producen en la dinámica natural.

Dado que los ritmos de la erosión costera dependen del tipo de obras que se hayan realizado sobre la costa y la resistencia de los materiales con los que dichas obras (espigones o defensas) fueron construidas. A su vez, a esto debe agregarse el estudio de los efectos que las tormentas costeras pueden ocasionar en la comunidad, y por sobre todo, cuando no existe tiempo suficiente para que se produzcan recuperaciones de los daños producidos en la costa.

En el caso analizado de Playa Magagna, en el año 2001 un grupo de vecinos encaró diversas acciones para dar solución a las intervenciones que los propietarios del sector de acantilados realizan sobre las laderas de las barrancas, y que contribuyen a inducir procesos de peligro. Un ejemplo de esas acciones fue la construcción de un albardón en el tope de los acantilados, con el objetivo de disminuir la escorrentía superficial producida por precipitaciones extraordinarias sobre las laderas de las barrancas, y la consecuente disminución de la erosión hídrica y los fenómenos de remoción en masa.

Por ello, en la búsqueda de soluciones a problemas costeros de este tipo, la opinión de la comunidad debe ser considerara al momento de las propuestas de gestión. Lograr una participación activa y continua de las comunidades de Playa Unión y Playa Magagna, permitirá que las mismas se apropien de las acciones que se propongan para manejar la problemática vinculada a peligros por erosión en los espacios costeros analizados.

\section{BIBLIOGRAFÍA}

BURTON, I.; KATES, R. and WHITE, G. The environment as hazard. First Edition. New York: Oxford University Press, 1978.

CALVO GARCÍA TORNEL, F. Algunas cuestiones sobre geografía de los riesgos. Scripta Nova. Revista Electrónica de Geografía y Ciencias Sociales. [en línea] Barcelona: Universidad de Barcelona, 15 de noviembre de 1997, $\mathrm{n}^{\circ} 10$.

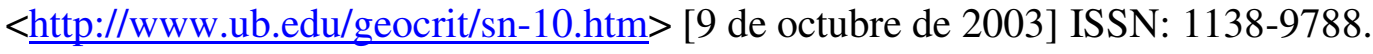

CARDONA, O. D. Evaluación de la amenaza, la vulnerabilidad y el riesgo. Elementos para el ordenamiento y la planeación del desarrollo. En MASKREY, A. (Ed). Los desastres no son naturales. Bogotá: La Red de Estudios Sociales en Prevención de Desastres en América Latina, 1993, p. 51-73. 
CODIGNOTTO, J. O. Erosión costera. En GONZÁLEZ, M. A. y BERJERMAN, N. J. (Ed.). Peligrosidad geológica en Argentina. Metodologías de análisis y mapeo. Estudio de casos. Buenos Aires: Asociación Argentina de Geología aplicada a la Ingeniería. Publicación especial n ${ }^{\circ}$ 14, 2004, p. 90-111.

DADON, J. R. El impacto del turismo sobre los recursos naturales en la costa pampeana argentina. En DADON, J. R. y MATTEUCCI, S. D. (Ed.). Zona costera de la pampa argentina. Buenos Aires: Lugar Editorial, 2002, p. 111-123.

ISLA, F. Erosión y defensas costeras. En ISLA, F. y LASTA, C. (Ed.). Manual de Manejo Costero para la provincia de Buenos Aires. Mar del Plata: Editorial Universitaria de Mar del Plata, 2006, p. 125-147.

KOKOT, R. Erosión en la costa patagónica por cambio climático. Revista de la Asociación Geológica Argentina, 2004, vol. 4, n 59, p. 715-726.

LAGUNAS, G. Análisis del sitio de Playa Magagna desde el punto de vista geomorfológico. Tesis de Licenciatura. Trelew: Departamento de Geografía, Universidad Nacional de la Patagonia San Juan Bosco. 1995

LAVELL, A. Degradación ambiental, riesgo y desastre urbano. Problemas y conceptos: hacia la definición de una agenda de investigación. En FERNANDEZ, M. A. (Comp.). Ciudades en Riesgo. Degradación Ambiental, Riesgos Urbanos y Desastres. Bogotá: Red de Estudios Sociales en Prevención de Desastres en América Latina, 1996, p. 1243.

MASKREY, A. Comunidad y desastres en América Latina: estrategias de intervención. En LAVELL, A. (Comp.). Viviendo en Riesgo. Comunidades vulnerables y prevención de desastres en América Latina. Bogotá: La Red de Estudios Sociales en Prevención de Desastres en América Latina, 1997, p. 14-38.

MONTI, A. Evaluación geoambiental preliminar de riesgo costero en playa Magagna, Chubut. Revista Asociación Argentina de Geología Aplicada a la Ingeniería y al Ambiente, 1999, $\mathrm{n}^{\circ}$ 13, p. 125-136.

MONTI, A. Edades 14C y ciclicidad de la acreción en depósitos costeros elevados. Revista de la Asociación Geológica Argentina, 2000, vol. 4, n 55, p. 403-406.

MONTI, A. y FERRARI, M. P. Riesgos, conflictos y políticas públicas vinculadas al uso urbano-turístico en el litoral Playa Magagna (Chubut, Patagonia). Boletín de la Sociedad Argentina de Estudios Geográficos, 2011, n 129, p. 45-62.

WILCHES CHAUX, G. La Vulnerabilidad Global. En MASKREY, A. (Comp.). Los desastres no son naturales. Bogotá: La Red de Estudios Sociales en Prevención de Desastres de América Latina. 1993, p. 9-50

ZUJAR, J. Métodos para el cálculo de la erosión costera, revisión de tendencias y propuestas. Boletín de la A.G.E., 2001, nº 30, p. 98-115. 
(C) María Paula Ferrari, 2012.

(C) GeoGraphos. Revista Digital para Estudiantes de Geografía y Ciencias Sociales, 2012.

\section{Ge Graphos}

REVISTA DIGITAL

PARA ESTUDIANTES DE GEOGRAFÍA Y CIENCIAS SOCIALES

ISSN: $2173-1276$ 